\title{
Exploring Undergraduates' Satisfaction with Library Resources and Services: A Case Study of the Science Library, University of Peradeniya, Sri Lanka
}

B. M. M. C. B. Hindagolla ${ }^{1}$

\begin{abstract}
This study investigated the level of undergraduates' satisfaction and their perceptions towards library resources and services provided by the Science Library, University of Peradeniya. The survey research method was adopted to achieve the above objectives. A questionnaire was administered to 442 undergraduates of the Faculty of Science. 371 duly filled questionnaires were returned, were then analyzed. The findings revealed that more than $60 \%$ of the undergraduates visited the library daily and weekly, while more than $80 \%$ of them visited the library for multiple purposes. Regarding the available resources, the majority of the undergraduates were satisfied with the library book collection, periodicals and available magazines. Yet, only $39 \%$ and $32 \%$ of students reported that they were satisfied with e-resources and audiovisual materials available in the library respectively. Considering the library services, the majority of respondents were satisfied with lending, reference, referral and photocopying services. However, $11 \%$ of them were not satisfied, where as $13 \%$ of the students were not even aware of online services provided by the library. Further, the findings demonstrated that limited number of
\end{abstract}

\footnotetext{
${ }^{1}$ Senior Assistant Librarian, Faculty of Science, University of Peradeniya. Email: menakah@pdn.ac.lk iD https://orcid.org/0000-0002-4358-6035 
computers, unavailability of Wi-Fi facilities, unawareness of the library website, difficulties of accessing the Internet and searching research articles were the main reasons for students' dissatisfaction. However, the majority of the undergraduates praised the library staff for offering an impressive service. The results proved that undergraduates have positive perceptions towards the library and its services. Based on the findings, some suggestions were made to increase user satisfaction and to enhance the library resources and service quality.

Keywords: User Satisfaction, Library Resources, Library Services, Science Undergraduates, University of Peradeniya, Sri Lanka 


\section{Introduction}

University libraries play a major role in providing information resources required for teaching, learning and research purposes of their community (Amarasekara \& Marasinghe, 2020). Currently, academic libraries are facing great challenges due to the global digital revolution. Users can now access library resources through online without coming to the library building (Chandrasekar \& Murugathas, 2012). As a result of this information revolution, university libraries now realize that they are not the sole providers of information services required by their users. At this juncture, it is important that the library management focuses on conducting user satisfaction studies which will determine factors that encourage or discourage the use of library resources and services. In addition, every year, new students enter the university with different levels of library usage and information searching skills (Ranawella \& Rajapaksha, 2017). Their expectations and perceptions vary a lot. Therefore, measuring user satisfaction periodically is important to understand user information needs and expectations. It is also helpful in updating library resources, and services.

These surveys will help library managers to evaluate the strengths and weaknesses of libraries and provide an opportunity to focus on enhancing user satisfaction (Miraj \& Naseer, 2013). Thus, the current study was conducted to identify whether users were satisfied or not satisfied with sources and services provided by the Science Library and to examine their perceptions regarding the library staff. A survey was carried out among undergraduates of the Faculty of Science, University of Peradeniya, Sri Lanka. This study will provide the library management with some clues on user expectations and needs to be incorporated to 
upgrade library resources and services. Further, the study will also contribute towards improving the quality and effectiveness of library services and encouraging good management practices of university libraries, which are important attributes for quality assurance accreditation in Sri Lanka. At the same time, the study will offer an opportunity to upgrade weakened areas which undergraduates have pointed out, and provide a chance to further strengthen the areas of services in which the users were satisfied.

\section{Objectives of the Study}

The general purpose of this study is to determine the undergraduates' satisfaction with information resources and services available in the Science Library, University of Peradeniya. The specific research objectives are:

- To investigate the purposes and the frequency of library visits by undergraduates

- To determine the level of satisfaction of students with regard to library resources and services

- To analyze undergraduates' perceptions towards the services offered by the library staff

\section{Review of Literature}

In the field of Library and Information Science, user satisfaction with library resources and services has become an important factor lately. Ample research has been conducted in recent years to evaluate library resources and services to identify user needs and expectations at local and international levels. However, this literature review focuses on library user 
satisfaction studies conducted by university libraries in Sri Lanka in chronological order.

Gunasekera (2010) carried out a questionnaire based survey to identify undergraduates' library usage of the Main Library, University of Peradeniya using 800 student sample. Among the study objectives, undergraduates' library satisfaction of available resources and services were assessed. Findings demonstrated that undergraduates were satisfied with the library cleanliness, lighting, seating capacity, service of the staff, opening hours and available security. On the other hand, users were somewhat satisfied with the availability of computers and photocopy service in the library. The author concluded that undergraduates were satisfied with the overall services and facilities available. However, undergraduates had not fully utilized available resources and services due to unawareness. The author also outlined the importance of conducting comprehensive information literacy programs to guide students regarding the resources and services of the library.

Chandrasekar and Murugathas (2012) conducted a user satisfaction survey to assess the library user satisfaction on currently available resources and services and to identify the unmet needs among the general degree Bio-science students at the University of Jaffna. A questionnaire was the main tool used for gathering data. Findings of the study revealed that the majority of the students visited the library daily or 2 to 3 times a week and the majority of them visited the library for multiple purposes. Many students visited the library for borrowing books and completing assignments. Further, findings indicated that $64 \%$ of the undergraduates were satisfied with the library collection. However, $63 \%$ of undergraduates were not satisfied with the electronic collection in the library. In addition, 
results indicated that respondents were satisfied with help of the library staff, procedures taken to locating information and services. But respondents showed their dissatisfaction on some services. Based on study findings authors strongly recommended that the library collection should be updated with current editions and enhance some services as well. In another study, Sivathaasan (2013) examined satisfactory levels of undergraduates at the Faculty of Management Studies \& Commerce regarding the facilities offered by the Main Library, University of Jaffna. The said study findings indicated that most students were relatively satisfied with the information resources, library environment and competence of library staff. According to that study library facilities had an impact on undergraduates' satisfaction at the rate of $20 \%$.

In 2013, Nawarathne and Singh carried out a survey on service quality and user satisfaction of university libraries in Sri Lanka. The main focus of the study was to find the level of user satisfaction towards library services, compare service quality \& user satisfaction, and analyze the overall service quality and satisfaction. Randomly selected two hundred undergraduates from three major universities of Sri Lanka were employed in this study. The study results showed that the library users were fairly satisfied with some services and they were not satisfied with the ventilation, collections, opening hours, number of service hours, number of books issued, printing \& scanning facilities, computer facilities, Internet access, and e-learning facilities. Yet, customer care of library staff and their positive responsiveness met students' expectations more than other services.

Further, Vijeyaluxmy (2015) conducted a survey to identify the information needs and the satisfaction levels of the students with library 
services using undergraduates from three major disciplines at the Trincomalee Campus of Eastern University of Sri Lanka. Findings demonstrated that the undergraduates had a moderate level of satisfaction regarding library materials collection, access to such material, library services and library environment. In addition, users were highly satisfied with library staff and library procedures. Users indicated that they had high expectations to receive more services from the library such as electronic resource collection, the Internet and computer facilities. Ranawella and Rajapaksha (2017) also conducted a survey among the first and third year undergraduates of two faculties of General Sri John Kothalawala Defence University to assess the use and user satisfaction of library resources and services at the Main Library. Findings of the study revealed that undergraduates were satisfied with the overall library resources, services, and facilities. Further, results showed that respondents were highly satisfied with the performance of the reference services, circulation services and online reservation services. However, one-fourth of respondents were dissatisfied with online library services, OPAC/web OPAC (Open Public Access Catalogue), and e-resource retrieval facility. The authors concluded that the library had a vital role to play in promoting library services and emphasized that the library should provide a quality service for its users.

In another study, Rubasinghe and Bodhinayake (2018) carried out a survey to identify the level of postgraduate students' satisfaction on library services. This study indicated that most students were satisfied with weekend services offered by the library. Majority of the respondents were satisfied with the seating capacity, efficient service in borrowing and returning and sanitary facilities. But majority of the respondents were not 
satisfied with opportunities available for remote access of electronic resources, the conduct of library orientation programs and its answering of user queries, OPAC and Web OPAC services, scanning services, displaying new arrivals and the number of books that can be borrowed. However, respondents were highly satisfied with the library environment and services provided by the library staff. Further, results indicated the respondents' overall satisfaction among faculties. It showed that respondents from the Faculties of Arts in three universities were satisfied with the available resources and services than other the once from two faculties. The level of satisfaction of the students from Science faculties was much less.

In a related study, Sritharan (2018) conducted a cross-sectional study to investigate the level of user satisfaction of available library eresources and services. A questionnaire was distributed among 100 medical officers using simple random technique. Findings revealed that about $60 \%$ and $50 \%$ of respondents strongly agreed with the free access to the Internet and subscribed electronic resources provided by library respectively. Only less than $50 \%$ of respondents satisfied with the awareness programs on availability of electronic resources, user education programs and current awareness services. Lack of computers in the library, lack of training, slow access and downloading speed and non-availability of remote access for subscribed electronic resources were identified as major issues by the respondents. Similarly, Amarasekara and Marasinghe (2020) examined the contentment of users with library services and resources of the Open University library of Sri Lanka. 357 of students and staff who were registered in the Main Library were the participants of the study. Study results indicated that respondents were mostly satisfied with 
the library staff, their performance as well as helpfulness. In addition to that student were fairly contented with the available library services, library website and its facilities. However, authors didn't analyze research findings according to the faculties. These findings corroborated the findings of Sivathaasan (2013). Both studies employed university undergraduates and they were commonly satisfied with the library facilities and library resources.

The above literature review demonstrated facts in support of user satisfaction of library resources and services available in the Sri Lankan university system. However, there have been a limited number of studies conducted on user satisfaction of library resources among Natural and Applied Science undergraduates in Sri Lanka. Further there has been only a single study carried out at University of Peradeniya using Arts undergraduates in 2010 by Gunasekera which examined user satisfaction towards the main library as one of the several study objectives. The current research entirely emphasized on examining the user satisfaction of library resources and services at the same university focusing on Natural and Applied Science undergraduates. Moreover, measuring satisfaction on services is vital important in library filed as libraries are providing services to public and specific group of people. Therefore, assessing users' satisfaction periodically is very important in enhancing quality of services effectively and continuously. In addition to that, the current study looked into undergraduates' emotions towards the library which was not covered under previous studies. Thus, the outcomes of the study can be used to improve the services of the Science Library and will contribute to the growing body of knowledge in the domain of user satisfaction on university library services as well. 


\section{Methodology}

The survey research design was applied in this study. The main group of the study was undergraduates of the Faculty of Science. The total number of undergraduates of the faculty was 1770 for the academic year $2019 / 2020$.

\section{Table 1}

Sample Selection of the Study

\begin{tabular}{lcc}
\hline \multicolumn{1}{c}{ Year of Study } & Total Population & Sample \\
\hline First Year & 502 & 126 \\
Second Year & 464 & 116 \\
Third Year & 463 & 115 \\
Fourth Year & 341 & 85 \\
\hline Total & 1770 & 442 \\
\hline
\end{tabular}

Out of the total population of the faculty, 442 undergraduates were selected as a convenient sample for the study. The non-probability sampling method was used and the data was collected during the first three months of the 2020 . However, it covered $25 \%$ of the total population of each batch according to year of study (Table 1).

The questionnaire was the main research tool used for collecting data. The questionnaire consisted of thirteen main questions regarding demographic data, frequency of library visit, purposes of library visit, level of satisfaction on resources and services, perception of library staff and any issues encountered by undergraduates. Most of the questions in the questionnaire were structured and few questions were open-ended. Data were collected from undergraduates who visited the library during the first 
three months of the year 2020.371 duly filled questionnaires were returned rendering a response rate of $84 \%$. Received data were analyzed using the Power Business Intelligence software and presented using frequency tables and basic statistics. Responses received to open-ended questions were analyzed using Word Tokenizer in Python and R-Language. Emotional Classification analysis and word cloud data visualization techniques were performed to analyze the comments given by respondents.

\section{Results and Discussion}

In terms of demographic findings, $62.8 \%$ of the respondents were female, and the remaining $37.2 \%$ were male. According to undergraduates' level of study, responded numbers are as follows:

\section{Table 2}

Number of Respondents According to Undergraduates' Year of Study

\begin{tabular}{lcc}
\hline \multicolumn{1}{c}{ Year of Study } & No. of Respondents (n) & Percentage (\%) \\
\hline First Year & $78 / 126$ & 62 \\
Second Year & $105 / 116$ & 91 \\
Third Year & $106 / 115$ & 91 \\
Fourth Year & $82 / 85$ & 96 \\
\hline Total & $371 / 442$ & 84 \\
\hline
\end{tabular}

Table 2 shows that the majority of the respondents were fourth year students $(96 \%)$ while the least number of respondents were first years $(62 \%)$. As first year students are newcomers to the library, they might have been reluctant to respond to the survey. 


\section{Frequency of Library Visit}

It is important to know that how often undergraduates visit the library for their learning and research purposes. Undergraduates were asked to indicate how often they visited the library. With regard to the frequency of library visits by the survey respondents, it was observed that $24 \%$ of students visited the library daily while $45 \%$ of students visited weekly (Figure 1). This finding indicated that more than $60 \%$ of undergraduates visited the library daily and weekly. However, $10 \%$ of students visited the library monthly while $7 \%$ of them are visited every other week. It was also noted that a small number of students visited the library once in every three to six months (Figure 1).

\section{Figure 1}

Frequency of Library Visit by Undergraduates

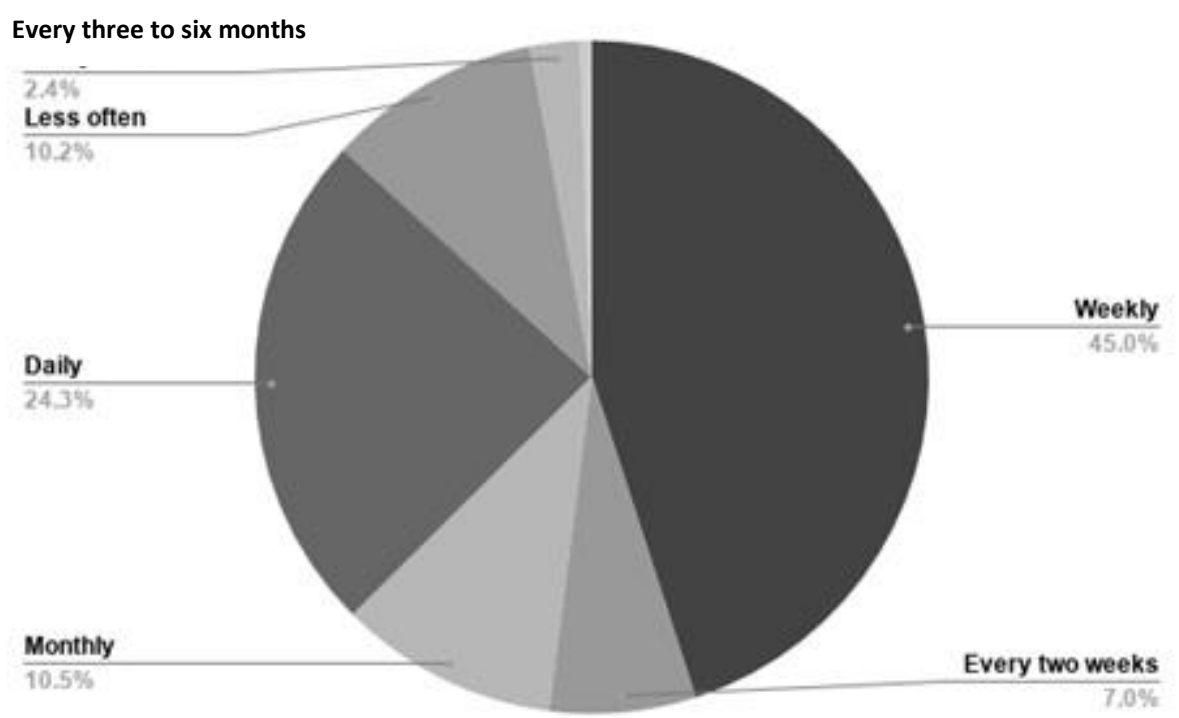

\section{Purpose of Visit to the Library}

It is essential to know why undergraduates are visiting the library because it indicates what information resources and services are required 
for them. Figure 2 shows the purpose of the visit to the library by undergraduates.

\section{Figure 2}

Purpose of Visit to the Library

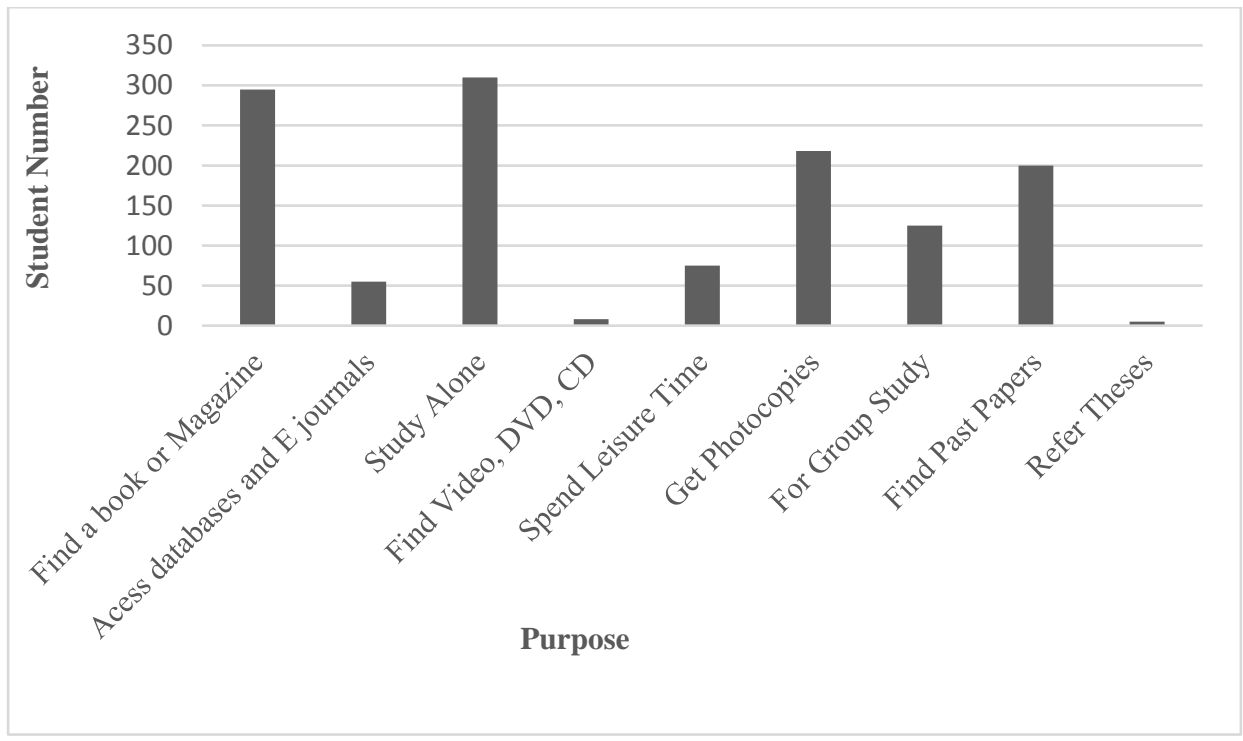

Students were asked to indicate multiple responses to the purpose of visit to the library. The majority of undergraduates visited the library to study alone 310 (84\%) and for searching books \& magazines 295 (80\%). Then getting photocopies and searching for past papers were the next popular activities among the undergraduates. However, only $55(14 \%)$ of undergraduates mentioned that accessing databases and e-journals were one of the purposes for visiting the library. Only $37 \%$ of students used the library for group discussions and studies. Accessing databases and ejournals, referring to theses, project reports and accessing audiovisual materials were not very popular among undergraduates. These indicated that students were not aware of the available resources in the library. In 
addition, difficulty in accessing resources and availability of remote access could be some of the other reasons.

\section{Undergraduates Level of Satisfaction Regarding Library Resources and Services}

\section{Resources Available in the Library}

Figure 3 shows the number of responses received from the students regarding the satisfaction level towards various resources available in the library. It was found that $120(32 \%)$ undergraduates were strongly satisfied and $236(64 \%)$ were satisfied with the book collection. Further, $31(8 \%)$ of students were strongly satisfied and $216(58 \%)$ were satisfied with the periodical collection in the library. In the same way, Chandrasekar and Murugathas (2012) had observed that a high percentage of students from the biological stream were satisfied with the library book collection.

\section{Figure 3}

Undergraduates' Satisfaction on Available Resources at the Library

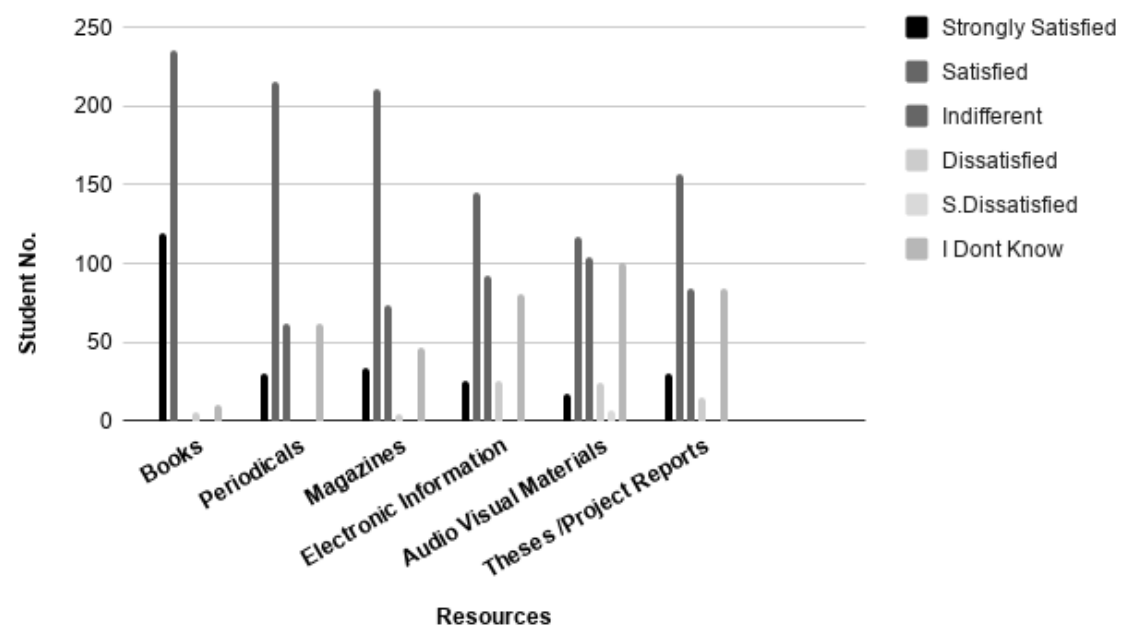


However, only 145 (39\%) and 117 (32\%) were satisfied with eresources and audiovisual materials, respectively. The majority of students did not know about e-resources and audiovisual materials available in the library. There were quite a few neutral reactions as well. When findings were cross checked with undergraduates' purpose of visiting the library (Figure 2), it indicated that only $55(14 \%)$ and $8(2 \%)$ of undergraduates visited the library to access e-resources and audiovisual materials respectively. It was evident that there may be some reasons for these low levels of satisfaction towards these resources. Thus, library management should investigate these factors thoroughly.

\section{Services Provided by the Library}

Figure 4 indicates the level of satisfaction of students with services offered by the library. It was observed that $238(64 \%)$ and $220(59 \%)$ of the respondents were satisfied with the lending services and reference services respectively.

\section{Figure 4}

Undergraduates' Satisfaction on Services Provided by the Library

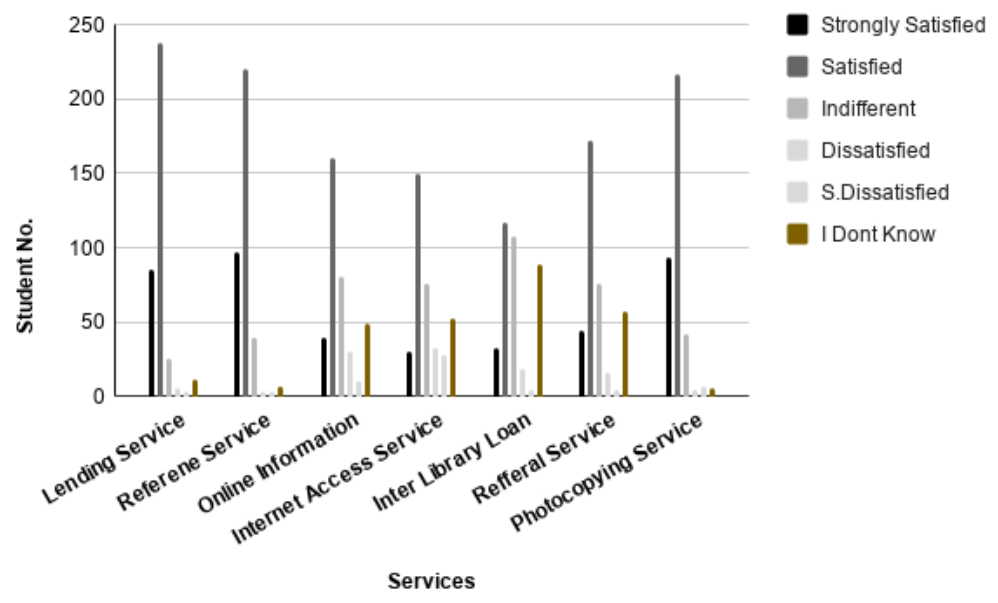


Moreover, the majority of students were satisfied with the photocopying service 217 (58\%) and referral service 172 (46\%) provided by the library. However, $41(11 \%)$ of the respondents were not satisfied with online services such as access to databases, e-journals, digital library and document delivery service provided by the library. Also, $49(13 \%)$ of the students were not aware and $81(22 \%)$ of the students had a neutral idea about online services provided by the library. Further, 108 (29\%) of the students had a neutral idea and 23\% were not aware of the Inter Library Loan (ILL) facilities. This implies that even though the library conducts awareness programs to promote library services, findings showed that many students had not grasped this information properly. Thus, library management should adopt proper mechanisms to keep students informed about these facilities regularly.

\section{Figure 5}

Comments Made by the Respondents on their Dissatisfaction Regarding Services Provided by the Library

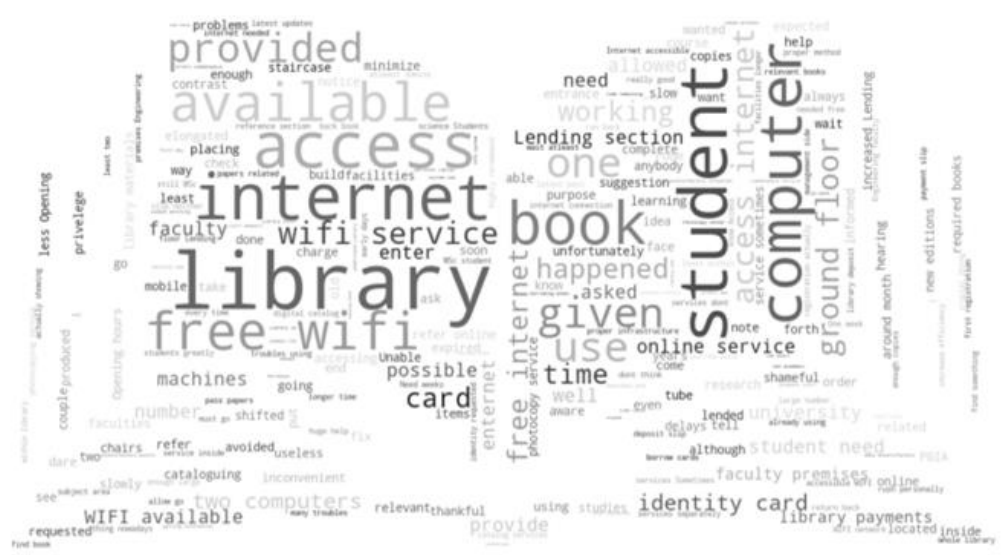


Further, in this study, students were asked to explain the reasons for their dissatisfaction with the above mentioned services. Only 76 students recorded their comments. According to the comments given by the respondents, the Word Cloud data visualization technique was performed. World Clouds are useful in analyzing any kind of text data including essays and written responses to opinion questions (Depaolo \& Wilkinson, 2014). By analyzing the results of Word Clouds (Figure 5), it was observed that a high frequency of words which appear in larger text, such as the Internet, free Wi-Fi, student computers, library website, online access, research articles access were indicated as not satisfactory. The majority of respondents mentioned that they faced difficulty in using available computers. They had to spend a lot of time to access computers in the library. Further, students claimed that non availability of Wi-Fi facilities in the library was a big shortcoming. Therefore, accessing the Internet was difficult for them without their phones. They mentioned this as unacceptable. As shown in Figure 3, only less than $50 \%$ of students were satisfied with accessing online resources. Apart from these, others were not aware of the library website and services offered. This was further proved through the comments made by 58 respondents regarding the online services offered by the library. According to Figure 6, undergraduates were having problems with using the library website, online catalogue, and online journals. It is an alarming situation that the library management has to rethink. Library management should educate students on getting familiar with the library website, e-journals, databases and other online services. 


\section{Figure 6}

Comments Made by the Respondents Regarding Online Services Provided by Library

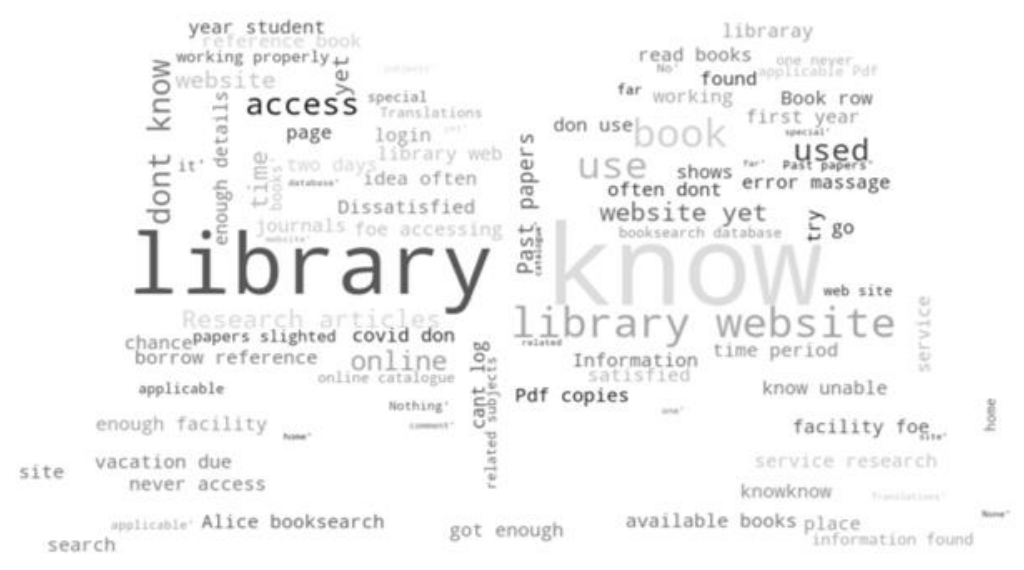

\section{Undergraduates Perceptions on Library Staff}

Services offered by the library staff perceived by users can have a significant impact on user satisfaction (Andaleeb \& Simmonds, 1998). Figure 7 indicates that, over $80 \%$ of respondents had positive perceptions towards the services offered by the library staff. Respondents strongly agreed or agreed that library staff was friendly and helpful 91\% (336), experienced and well trained $85 \%$ (315) and responds effectively and efficiently to users' requirements $80 \%$ (300). These findings were in par with results of the studies conducted by Gunasekara (2010), Sivathaasan (2013), Vijeyalaxmy (2015) and Amarasekara and Marasinghe (2020). 


\section{Figure 7}

Undergraduates' Perceptions Towards the Library Staff

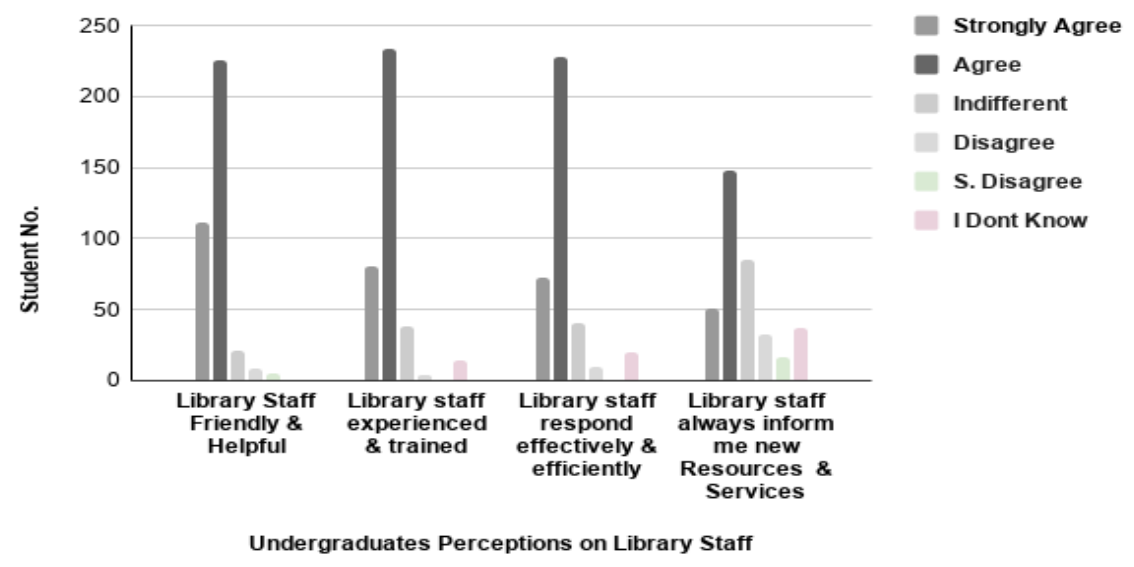

Further, in this study respondents were asked to write their comments regarding the library resources, services and its staff. 54 of the respondents replied. Comments were analyzed using emotion and sentiment classification tests (Mohammad \& Turney, 2010). Emotions may be expressed by a person's speech, facial expressions and written text (Shivhare \& Khethawat, 2012). The detection of human sentiment in texts is an important aspect to identify their positive or negative connotation towards any particular subject or an issue (Shivhare \& Khethawat, 2012). Therefore, this study classified comments given by the respondents using the "afinn" lexical affinity method (Nielsen, 2011) in order to identify whether the undergraduates 'sentiment towards the library was positive, negative or neutral'. Figure 8 shows the comparison of the proportion of words associated with each emotion in the comments section of the questionnaire. The emotions, 'trust' and 'positive' showed that the words associated with such emotions constituted over more than 50 times in the comments. On the other hand, 'disgust', 'anger' and 'fear' represented by 
short bars showed that words associated with such negative emotions constituted less than 30 times in the comments.

\section{Figure 8}

Emotions Classified Based on Comments Given by Respondents

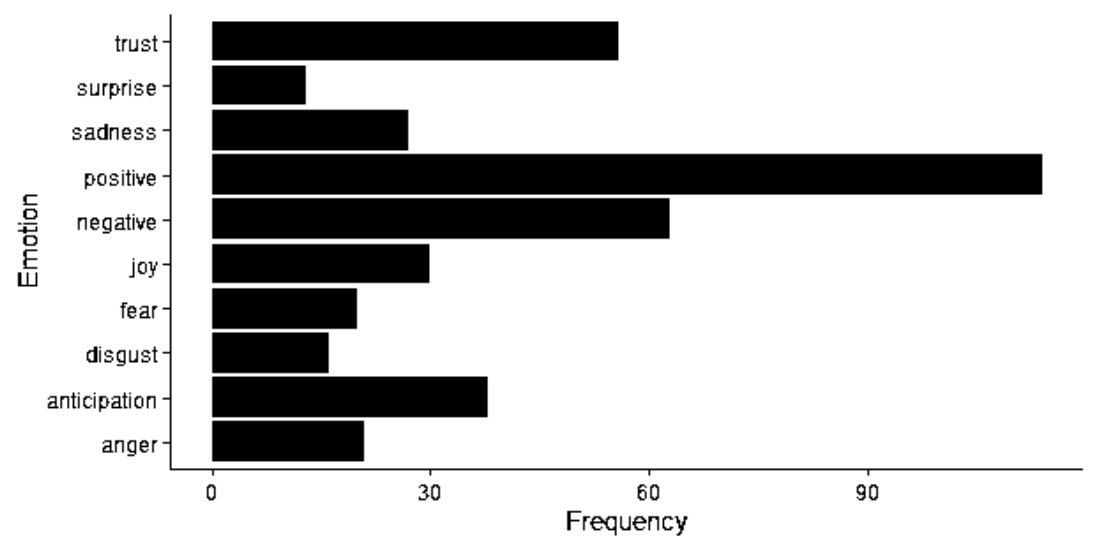

Table 3

Number of Meaningful Words Classified Based on Comments

\begin{tabular}{lcc}
\hline \multicolumn{1}{c}{ Emotion } & No. of Words & Percentage (\%) \\
\hline Positive & 114 & 29 \\
Negative & 63 & 16 \\
Trust & 56 & 14 \\
Surprise & 13 & 3 \\
Sadness & 27 & 7 \\
Joy & 30 & 7.5 \\
Fear & 20 & 5 \\
Disgust & 16 & 4 \\
Anticipation & 38 & 9.5 \\
Anger & 21 & 5 \\
\hline Total & 398 & 100 \\
\hline
\end{tabular}


Overall words such as 'positive' (29\%), 'trust' (14\%), 'anticipation' (9\%), ‘joy' (7\%), 'surprise' (3\%) associated with positive emotions cumulated for more than $55 \%$ of meaningful words, which is a positive sign towards the library (Table 3 ). Therefore, these findings proved that undergraduates had a positive perception towards the library and its services.

\section{Conclusion and Recommendations}

The main focus of the study was to determine level of undergraduates' satisfaction with information resources and services of the Science Library, University of Peradeniya. Based on the findings, it revealed that the majority of the undergraduates of the Faculty of Science visited the library daily and weekly. At the same time, results showed that the majority of the undergraduates visit the library to search for books \& magazines, to study alone and to obtain photocopies. Further, findings showed that undergraduates were satisfied with the library resources and services. Library book collection, periodicals and magazine collection were students' most satisfied resources. However, only less than $50 \%$ of undergraduates were satisfied with e-resources and audiovisual materials. It was evident through the findings that lending and reference services were the most satisfactory services provided by the library. In addition, most students were satisfied with photocopying and referral services. However, online services were not popular among them. Also, most students were unaware and had an in different opinion about ILL services. Limited number of computers, unavailability of Wi-Fi facilities, unawareness of library website, difficulties in accessing the Internet and searching for research articles were identified as reasons for their dissatisfaction towards online services. The majority of the undergraduates 
perceived the services offered by the library staff as excellent. Experienced and trained, efficient \& effective, friendly and helpful were the qualities of the library staff which were mostly admired by the undergraduates. It is a positive indication that library has responsible and responsive staff members who possess good customer care qualities. Overall, undergraduates of the faculty had positive attitudes towards the library and its resources, services and staff.

Based on the findings, it shows that some areas need to be improved and strengthened. It recommends some suggestions to be proposed to improve the existing resources and services of the library. Books are the main items of a library. The majority of students visit the library to borrow or refer books. Therefore, library management should focus on updating the existing collection with new editions and removing outdated ones. Further, library collection should be assessed frequently to determine its adequacy and relevance to the requirements of current degree programs. This will be useful in increasing the level of student satisfaction. It was revealed that many students were not satisfied with available eresources and audiovisual materials compared with other resources. It is suggested that paying more attention is needed on educating students about available electronic resources and services offered online. Hence, regular awareness programs, practical training sessions on electronic resources, program regarding how to search information on journals and databases and what services can be obtained using library online services should be organized to teach undergraduates. Apart from library orientation programs there should be a periodic discussion program with undergraduates in order to educate them on library services and resources. It will be a good platform for students to raise their issues and suggestion. 
Their complaints and suggestions may contribute to making changes and improvements in the library. There was a good response received from undergraduates regarding assistance offered by the library staff. This means that the library staff provides effective and efficient services to fulfill information requirements of the users. In order to maintain and increase the satisfaction level of undergraduates towards the staff, the members of the staff should be trained in maintaining and improving the services provided to the library users.

The library management should take necessary action to develop infrastructure facilities of the library which were mentioned by undergraduates. The number of computer terminals in the library should be increased which will then decrease the waiting time of students. Also, library management has to take necessary action to provide Wi-Fi facilities to library users. There appears to be a high demand from students, it will be necessary to popularize library resources and services.

The population used in this study was limited to undergraduates who visited the library during first quarter of 2020 in the Faculty of Science, University of Peradeniya. It could be repeated by using other categories of users in the faculty, such as Postgraduate students, academic \& non-academic staff and other attributes could be added to the questionnaire as well. Likewise, this study could be carried out in other Science based faculties in the University of Peradeniya which will help understand the user satisfaction behavior and their expectations towards the respective libraries and their services. 


\section{References}

Amarasekara, K., \& Marasinghe, K. (2020). User satisfaction of library resources and services: Survey conducted in main library of the Open University of Sri Lanka. Journal of the University Librarians Association of Sri Lanka, 23(2), 27-46. http://doi.org/ 10.4038/jula.v23i2.8007

Chandrasekar, K., \& Murugathas, K. (2012). An assessment of user satisfaction on library services: A case study of undergraduate Biology students at the University of Jaffna. Journal of the University Librarians Associations of Sri Lanka, 16(1), 34-458.

Depaolo, C. \& Willkinson, K. (2014). Get your heads in to the clouds: Using word clouds analyzing qualitative assessment data. TechTrends, 58(3), 38-44.

Gunasekera, C. (2010). Students' usage of an academic library: A user survey conducted at the Main Library University of Peradeniya. Journal of the University Librarians Association of Sri Lanka, 14(1), 43-60.

Miraj, M. \& Naseer, M. (2013). Library services and user satisfaction in developing countries: A case study. Health Information Libraries Journal, 30, 318-326.

Mohammad, S. M. \& Turney, P. D. (2010). Emotions evoked by common words and phrases: Using mechanical Turk to create an emotion lexicon. In D. Inkpen \& C. Strapparava (Eds.), Proceedings of the NAACL-HLT 2010 Workshop on Computational Approaches to Analysis and Generation of Emotion in Text (26-34). Association for Computational Linguistics. https://www.aclweb.org/ anthology/W10-0204.pdf 
Nawarathne, I., \& Singh A. P. (2013). Users' satisfaction of the academic library services in Sri Lanka. PERAL-A Journal of Library and Information Science, 7(2), 103-112.

Nielsen, F. A. (2011). Evaluation of a word list for sentiment analysis in Microblogs. In M. Rowe, M. Stankovic, A. Dadzie \& M. Hardey (Eds.), Proceedings of the ESWC2011 Workshop on 'Making Sense of Micro posts': Big things come in small packages (pp.93-98). http://arxiv.org/abs/1103.2903

Ranawella, T., \& Rajapaksha, M. (2017). Use and user satisfaction with library services and resources at the main library of the General Sir John Kotelawala Defense University, Sri Lanka. Journal of the University Librarians Association of Sri Lanka, 20(2), 28-45.

Rubasinghe, S., \& Bodhinayake, D. (2018). Postgraduate students' satisfaction with Library resources and services in Sri Lankan universities (with reference to universities of Keleniya, Ruhuna and Sri Jayewardenepura). International Journal of Management and Applied Science, 4(5), 5-8.

Sivathaasan, N. (2013). Satisfactory level of undergraduate students with academic library: A case study of Faculty of Management Studies and Commerce, University of Jaffna, Sri Lanka. Global Journal of Management and Business Research Administration and Management, 13(5), 63-69. http://repo.lib.jfn.ac.lk/xmlui/handle/ $123456789 / 649$

Sritharan, T. (2018). Evaluation of usage and user satisfaction on electronic information resources \& services: A study at Postgraduate Institute of Medicine Library, University of 
Colombo. Journal of the University Librarians Association of Sri Lanka, 21(2), 73-88.

Vijeyaluxmy, S. (2015). Students' satisfaction with library services in an academic library: Special reference to Trincomalee Campus. Paper presented at 5th International Symposium, SEUSL, Oluvil. http://www.seu.ac.lk/researchandpublications/symposium/5th/ libraryandinformationscience/13.pdf 